\title{
Peliculização de sementes de tomate associada ao paclobutrazol
}

\author{
Aniela Pilar Campos de Melo $\left({ }^{1 *}\right)$; Alexsander Seleguini $\left({ }^{1}\right)$, Valquiria da Rocha Santos Veloso( $\left.{ }^{2}\right)$ \\ (') Universidade Federal de Goiás (UFG), Escola de Agronomia, Setor de Horticultura, 74690-900 Goiânia (GO), Brasil. \\ (2) UFG, Setor Fitossanitário, 74690-900 Goiânia (GO), Brasil. \\ (*) Autora correspondente: aniela.pcdmelo@gmail.com
}

Recebido: 17/abr./2014; Aceito: 5/maio/2014

\begin{abstract}
Resumo
O tratamento de sementes com paclobutrazol (PBZ) deve ser aprimorado e tecnologias de recobrimento, como a peliculização, podem ser promissoras para aplicar uniformemente e fixar esse regulador no tegumento das sementes sem permitir um contato prejudicial ao embrião. Assim, determinaram-se os efeitos da peliculização de sementes com paclobutrazol no potencial fisiológico de sementes de tomate e as suas implicações no crescimento de mudas. Empregou-se o delineamento inteiramente casualizado, em esquema fatorial 2 × 4, sendo presença e ausência do polímero de revestimento Disco AG Red L-203 ${ }^{\circledR}\left(0\right.$ e $150 \mathrm{~mL} \mathrm{~kg}^{-1}$ de semente) e quatro concentrações de paclobutrazol - PBZ (0, 38,5, 76,9 e 115,4 mg L-1). A interação entre os fatores (peliculização x concentrações de paclobutrazol) ocorreu somente para a variável condutividade elétrica. Independentemente da concentração, o paclobutrazol reduziu a germinação, emergência de plântulas, altura de parte aérea, área foliar e propiciou um aumento na detecção de clorofila. A peliculização não interfere na ação do paclobutrazol sobre as sementes. O paclobutrazol é eficiente no condicionamento da altura de mudas mas prejudica a germinação e o vigor de sementes.
\end{abstract}

Palavras-chave: Solanum lycopersicum L., recobrimento de sementes, regulador de crescimento, germinação, vigor.

\section{Film coating of tomato seeds of the associated paclobutrazol}

\begin{abstract}
Seed treatment with paclobutrazol (PBZ) should be enhanced and coating technologies, such as film coating can be applied uniformly and promising to fix this regulator in the seed coat without allowing a contact damaging the embryo. The objective of this research was to determine the effects of film coating with paclobutrazol on physiological potential of tomato seeds and its implications on the growth seedlings. A randomized experiment design was applied in a factorial $2 \times 4$ scheme, presence or absence of the polymer coating Disco AG Red $\mathrm{L}-203^{\circledR}\left(0\right.$ or $150 \mathrm{ml} \mathrm{kg}^{-1}$ seed) and four concentrations of paclobutrazol - PBZ $\left(0,38,5,76,9\right.$ and $\left.115,4 \mathrm{mg} \mathrm{L}^{-1}\right)$. The interaction between factors (film coating x paclobutrazol concentrations) occurred only for variable electrical conductivity. Regardless of the concentration, paclobutrazol reduced germination, seedling emergence, height, leaf area and led to an increase in the detection of chlorophyll. Film coating does not interfere with the action of paclobutrazol on the seeds. Paclobutrazol is effective in seedling growth control, but affect the germination and seed vigor.
\end{abstract}

Key words: Solanum lycopersicum L., seed coating, growth regulators, germination, vigor.

\section{INTRODUÇÃO}

O sucesso da tomaticultura depende de inúmeros fatores, que vão desde a escolha do campo de produção à sua aceitaçáo pelo consumidor nas gôndolas dos mercados. Nesse cenário a produção de mudas é fundamental para a viabilidade produtiva da cadeia. As mudas devem ser originárias de sementes de alta qualidade e produzidas preferencialmente sob ambiente protegido.

Uma das principais problemáticas observadas na produção de mudas é o estiolamento da parte aérea devido ao excesso de crescimento vegetativo. Esse desequilíbrio ocasiona a formação de mudas frágeis, alongadas e mais suscetíveis a estresses bióticos e abióticos no transplantio
(Seleguini et al., 2013). O condicionamento químico com reguladores de crescimento é uma alternativa viável e, para solucionar essa dificuldade, o paclobutrazol pode destacar-se nesse contexto (Latimer, 1991).

O paclobutrazol proporciona a inibição da biossíntese de ácido giberélico (Rademacher, 2000). O alongamento caulinar é minimizado devido ao decréscimo das atividades meristemáticas em regiōes apicais e subapicais (Arney e Mancinelli, 1966) e diminuição dos teores de celulose na parede celular (Wang et al., 1986). Assim, na produção de mudas de tomate em ambiente protegido, o uso do paclobutrazol pode ser mais uma ferramenta para favorecer 
o transplantio e o estabelecimento das plântulas no campo (Seleguini et al., 2013).

A aplicação de paclobutrazol por meio de pulverizaçôes foliares e/ou molhamento de substrato pode ocasionar a acumulaçáo de resíduos em partes vegetais comercializáveis, principalmente em frutos (Yeshitela et al., 2004). Quando a veiculação do paclobutrazol ocorre por meio do tratamento de sementes, verifica-se a adequação satisfatória na altura de plântulas e os teores residuais em frutos não ultrapassam os níveis de segurança estabelecidos por agências internacionais como a United States Environmental Protection Agency US-EPA (Magnitsky et al., 2006b). No entanto, efeitos deletérios na germinaçấo de sementes e na emergência de plântulas são observados devido ao efeito antigiberelina no embriāo (Pill e Gunter, 2001). Assim, o tratamento de sementes com paclobutrazol deve ser aprimorado e tecnologias de recobrimento, como a peliculização, podem ser promissoras para aplicar uniformemente e fixar esse regulador no tegumento das sementes sem permitir um contato prejudicial ao embrião.

Diante do exposto, objetivou-se verificar os efeitos da peliculização de sementes com paclobutrazol no potencial fisiológico de sementes de tomate e as suas implicaçóes no crescimento de mudas.

\section{MATERIAL E MÉTODOS}

Avaliaram-se as respostas de sementes de tomate (cultivar Kada Gigante) peliculizadas associadas a concentraçóes crescentes de paclobutrazol. Empregou-se o delineamento inteiramente casualizado, em esquema fatorial $2 \times 4$, sendo presença ou ausência do polímero de revestimento Disco AG Red L-203 (Incotec Holding BV, Enkhuizen, Países Baixos) (0 e $150 \mathrm{~mL} \mathrm{~kg}^{-1}$ de sementes) e quatro concentraçóes de paclobutrazol - PBZ (0, 38,5, 76,9 e 115,4 $\left.\mathrm{mg} \mathrm{L}^{-1}\right)$, com cinco repetiçōes.

Inicialmente, a quantidade de película de revestimento foi diluída em $15 \mathrm{~mL}$ de água destilada e posteriormente misturada a $50 \mathrm{~mL}$ de solução de paclobutrazol nas seguintes concentraçóes: 0 , 50, 100 e $150 \mathrm{mg} \mathrm{L}^{-1}$. Considerou-se que a mistura dessas soluçóes de solutos diferentes não proporciona ocorrência de reação química, portanto as concentraçóes finais do paclobutrazol foram de aproximadamente $0,38,5$, 76,9 e $115,4 \mathrm{mg} \mathrm{L}^{-1}$.

Foram utilizadas três gramas de sementes por tratamento. A adesão da mistura polímero-paclobutrazol às sementes ocorreu por agitaçáo (Mesa Agitadora Orbital de Bancada, NT 145), em erlenmeyer de vidro, por 10 minutos a $80 \mathrm{rpm}$. Posteriormente, as sementes foram secas em papel de filtro por 24 horas a $22^{\circ} \mathrm{C}$. O grau de umidade foi determinado por meio do método de estufa a $105^{\circ} \mathrm{C}$, por 24 horas, sendo utilizadas duas subamostras de 50 sementes.

\section{Avaliação do potencial fisiológico de sementes}

\section{Teste de germinação}

250 sementes (cinco repetiçóes de 50 sementes por tratamento) foram semeadas em caixas de poliestireno - gerbox $(11 \times 11 \times 3,5 \mathrm{~cm})$, sobre três camadas de papel germitest. O substrato foi umedecido com água destilada equivalente a 2,5 vezes a sua massa seca. As caixas foram mantidas em câmara incubadora BOD a $25^{\circ} \mathrm{C}$, com fotoperíodo de 12 horas. As avaliaçóes consistiram na identificação de plântulas normais aos cinco (primeira contagem de germinação) e 14 dias após a semeadura, sendo os resultados expressos em porcentagem.

\section{Condutividade elétrica}

Foram usadas cinco repetiçóes de 50 sementes pesadas com precisão de $0,0001 \mathrm{~g}$ e colocadas para embeber em copos plásticos $(100 \mathrm{~mL})$ contendo $75 \mathrm{~mL}$ de água destilada durante 24 horas a $25^{\circ} \mathrm{C}$. A medição de condutividade elétrica foi efetuada por meio de condutivímetro portátil (PHTEK CD203) e os resultados foram expressos em $\mu \mathrm{Sm}^{-1} \mathrm{~g}^{-1}$.

\section{Teste de frio sem "terra"}

Cinco repetiçóes de 50 sementes foram distribuídas em substrato rolo de papel toalha umedecido com água destilada equivalente a 2,5 a massa do papel seco. Após a semeadura, os rolos foram colocados em sacos plásticos e permaneceram a $10{ }^{\circ} \mathrm{C}$ em câmara de resfriamento por sete dias. Depois foram transferidos para câmara incubadora $\mathrm{BOD}$ a $25^{\circ} \mathrm{C}$, onde permaneceram por mais sete dias. Os resultados foram expressos em porcentagem de plântulas normais.

\section{Emergência de plântulas em casa de vegetação}

Realizou-se a semeadura em bandejas de isopor de 288 células $\left(10 \mathrm{~cm}^{3}\right.$ célula $\left.{ }^{-1}\right)$, preenchidas com substrato Qualifibra ${ }^{\oplus}$, distribuindo-se uma semente por célula. Foram utilizadas cinco repetiçóes de 36 sementes. As bandejas foram mantidas em ambiente protegido. A emergência de plântulas foi avaliada a cada dois dias, do quinto ao $15 .^{\circ}$ dia após a semeadura, para cálculo do índice de velocidade de emergência (Maguire, 1962).

\section{Avaliação do crescimento de mudas}

Aos 28 dias após a semeadura procedeu-se à análise de crescimento. Determinou-se: a massa de matéria fresca total (g); a massa de matéria seca total, parte aérea e radicular (mg); 
a relação entre massa de matéria seca de raiz e massa de matéria seca de parte aérea; o diâmetro de hipocótilo ( $\mathrm{mm})$; a altura de parte aérea $(\mathrm{cm})$; a relação entre diâmetro de hipocótilo e a altura de parte aérea; o comprimento radicular $(\mathrm{cm})$; a razão de área foliar $\left(\mathrm{cm}^{2} \mathrm{~g}^{-1}\right)$; e o teor de clorofila (SPAD).

Amostraram-se, de cada repetição, oito mudas. Essas foram pesadas em balança analítica (precisão de $0,001 \mathrm{~g}$ ), para obtenção de massa de matéria fresca total. A altura de parte aérea e o comprimento radicular foram obtidos com o auxílio de régua graduada em milímetros. Para a determinação do diâmetro de hipocótilo empregou-se paquímetro digital. A área foliar foi mensurada por meio de scanner (Area Meter, CI-202, CID BIO-SCIENCE). O conteúdo total de clorofila foi obtido por meio do medidor SPAD-502 (Konina Minolta). Posteriormente, as mudas foram acondicionadas em sacos de papel e submetidas ao método estufa $\left(60^{\circ} \mathrm{C}, 72 \mathrm{~h}\right)$ para determinação da massa de matéria seca de parte aérea e sistema radicular (Benincasa, 2003). A razão de área foliar (RAF) foi calculada por meio da razão entre a área foliar e a massa de matéria seca total (Benincasa, 2003).

Inicialmente, os dados obtidos foram submetidos aos testes de Lilliefors (Normalidade) e Barlett (Homogeneidade de variância) para verificarem-se as pressuposiçóes da análise da variância. Todos esses requisitos foram atendidos e, portanto, os dados não foram transformados. A significância dos efeitos dos tratamentos foi determinada pelo Teste F, sendo que para o fator concentraçóes de paclobutrazol foram ajustadas regressóes polinomiais.

\section{RESULTADOS E DISCUSSÃO}

A interação entre os fatores (peliculização x concentrações de paclobutrazol) ocorreu somente para a variável condutividade elétrica $(\mathrm{p}<0,01)$ (Tabelas 1,2 e 3$)$. As demais variáveis foram analisadas considerando-se as médias de cada fator.

$\mathrm{O}$ revestimento de sementes não alterou as variáveis relacionadas a germinação e emergência de plântulas (Tabela 1). O polímero não impediu a difusão do oxigênio e/ou mudou a permeabilidade do tegumento, que poderiam prejudicar o desempenho germinativo e o estabelecimento de plântulas (Magnitsky et al., 2006a; Willenborg et al., 2004). Resultados semelhantes foram observados para as culturas do milho (Pereira et al., 2005), algodão (Lima et al., 2006), alface (Diniz et al., 2006), soja (Pereira et al., 2010) e cenoura (Hölbig et al., 2010).

$\mathrm{O}$ recobrimento de sementes pode alterar a absorção de umidade no substrato e/ou solo, prejudicando a germinação e emergência (Dizaj, 2010). Além disso, durante a embebição, alguns materiais utilizados desintegram-se formando uma "papa" (massa sem resistência) que limita a passagem de oxigênio e umidade para o embrião (Sampaio e Sampaio, 2009).

Concentraçóes crescentes de paclobutrazol prejudicaram as porcentagens e velocidades de germinação (primeira contagem de germinação) e emergência (Tabela 1). A embebição propiciou a penetração desse regulador no interior da semente, resultando na diminuição dos níveis de giberelinas endógenas e consequente prejuízo ao alongamento do eixo embrionário, à síntese e atividade de enzimas envolvidas na germinação (Bewley e Black, 1994; Pill e Gunter, 2001). Pasian e Bennett (2001) afirmam que além desse contato deletério com o embrião, há uma tendência de migração do produto do tegumento da semente para o meio de crescimento. Esses autores relatam que no substrato papel usado no teste de germinação a concentração do paclobutrazol ao redor das sementes alcança níveis considerados inibitórios. Já o substrato utilizado para o teste de emergência funciona como um material adsorvente do excesso de regulador lixiviado

Tabela 1. Potencial fisiológico de sementes de tomate cultivar Kada Gigante peliculizadas com paclobutrazol: germinação (G), primeira contagem de germinação (1C), teste de frio (TF), condutividade elétrica (CE), emergência de plântulas (E) e índice de velocidade de emergência (IVE)

\begin{tabular}{|c|c|c|c|c|c|c|}
\hline Tratamentos & $\begin{array}{c}G \\
(\%)\end{array}$ & $\begin{array}{l}1 \mathrm{C} \\
(\%)\end{array}$ & $\begin{array}{l}\text { TF } \\
(\%)\end{array}$ & 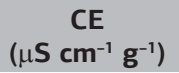 & $\begin{array}{c}E \\
(\%)\end{array}$ & IVE \\
\hline \multicolumn{7}{|l|}{ Polímero (P) } \\
\hline Ausência & 75 & 46 & 58 & 177,91 & 95 & 13,00 \\
\hline Presença & 75 & 47 & 39 & 130,28 & 91 & 11,88 \\
\hline Teste F & 0,004 ns & 0,02 ns & $49,39^{* *}$ & $14,76^{* *}$ & $2,59 \mathrm{~ns}$ & $2,91 \mathrm{~ns}$ \\
\hline \multicolumn{7}{|l|}{ Paclobutrazol (Z) } \\
\hline 0 & 95 & 74 & 67 & 116,58 & 99 & 17,09 \\
\hline 38,5 & 75 & 40 & 41 & 154,46 & 93 & 11,36 \\
\hline 76,9 & 68 & 34 & 40 & 181,62 & 91 & 10,93 \\
\hline 115,4 & 62 & 40 & 46 & 163,72 & 89 & 10,37 \\
\hline Teste F & $23,53^{* *}$ & $20,19^{* *}$ & $23,08^{* *}$ & $4,89^{* *}$ & $3,28^{*}$ & 22,83 ** \\
\hline Regressão & L & Q & Q & Q & L & Q \\
\hline Teste F (P x Z) & $0,92 \mathrm{~ns}$ & 1,63 ns & $1,72 \mathrm{~ns}$ & $10,20^{* *}$ & $0,86 \mathrm{~ns}$ & $1,00 \mathrm{~ns}$ \\
\hline CV (\%) & 12,42 & 27,74 & 17,23 & 25,44 & 7,91 & 16,63 \\
\hline
\end{tabular}

* significativo $(\mathrm{p}<0,05)$; ${ }^{* *}$ significativo $(\mathrm{p}<0,01)$; ns - não significativo; $\mathrm{L}$ - modelo linear; $\mathrm{Q}$ - modelo quadrático. 
Tabela 2. Diâmetro de hipocótilo (DH), altura de parte aérea (AP), relação entre diâmetro de hipocótilo e altura de parte aérea (DH/AP), taxa de crescimento absoluto (TCA), área foliar (AF), área radicular (AR) e comprimento radicular (CR) de mudas de tomate (cultivar Kada Gigante) oriundas de sementes peliculizadas com paclobutrazol

\begin{tabular}{|c|c|c|c|c|c|}
\hline \multirow[t]{2}{*}{ Tratamentos } & $\begin{array}{c}\text { DH } \\
(\mathrm{mm})\end{array}$ & $\begin{array}{c}\text { AP } \\
(\mathrm{cm})\end{array}$ & DH/AP & $\begin{array}{c}\mathrm{AF} \\
\left(\mathrm{cm}^{2}\right)\end{array}$ & $\begin{array}{c}\text { CR } \\
(\mathrm{cm})\end{array}$ \\
\hline & \multicolumn{5}{|c|}{ planta $^{-1}$} \\
\hline \multicolumn{6}{|l|}{ Polímero (P) } \\
\hline Ausência & 1,79 & 7,30 & 0,25 & 9,36 & 8,41 \\
\hline Presença & 1,75 & 7,29 & 0,24 & 9,68 & 8,37 \\
\hline Teste F & $0,35 \mathrm{~ns}$ & $0,001 \mathrm{~ns}$ & $0,43 \mathrm{~ns}$ & $0,12 \mathrm{~ns}$ & $0,03 \mathrm{~ns}$ \\
\hline \multicolumn{6}{|l|}{ Paclobutrazol (Z) } \\
\hline 0 & 1,77 & 8,45 & 0,20 & 11,14 & 8,44 \\
\hline 38,5 & 1,84 & 7,61 & 0,24 & 10,11 & 8,54 \\
\hline 76,9 & 1,71 & 6,68 & 0,25 & 8,72 & 8,24 \\
\hline 115,4 & 1,76 & 6,42 & 0,27 & 8,11 & 8,35 \\
\hline Teste F & $0,87 \mathrm{~ns}$ & $11,61^{* *}$ & $10,75^{* *}$ & $2,42^{*}$ & $0,24 \mathrm{~ns}$ \\
\hline Regressão & - & $\mathrm{L}$ & $\mathrm{L}$ & $\mathrm{L}$ & - \\
\hline CV (\%) & 10,71 & 11,81 & 11,08 & 29,13 & 9,60 \\
\hline
\end{tabular}

${ }^{*}$ significativo $(\mathrm{p}<0,05) ;{ }^{* *}$ significativo $(\mathrm{p}<0,01)$; ns - não significativo; $\mathrm{L}$ - modelo linear.

Tabela 3. Massa de matéria fresca total (MFT), massa de matéria seca total (MST), massa de matéria seca de raiz (MSR), massa de matéria seca de parte aérea (MSPA), relação entre massa de matéria seca de raiz e massa de matéria seca de parte aérea (RMSR/MSPA), razão de área foliar (RAF) e teor de clorofila (C) de mudas de tomate (cultivar Kada Gigante) oriundas de sementes peliculizadas com paclobutrazol

\begin{tabular}{|c|c|c|c|c|c|c|c|}
\hline \multirow[t]{2}{*}{ Tratamentos } & $\begin{array}{l}\text { MFT } \\
\text { (g) }\end{array}$ & $\begin{array}{l}\text { MST } \\
\text { (mg) }\end{array}$ & $\begin{array}{l}\text { MSR } \\
\text { (mg) }\end{array}$ & $\begin{array}{l}\text { MSPA } \\
\text { (mg) }\end{array}$ & $\begin{array}{l}\text { RMSR/ } \\
\text { MSPA }\end{array}$ & $\begin{array}{l}\text { RAF } \\
\left(\mathrm{cm}^{2}\right)\end{array}$ & $\begin{array}{c}\mathrm{C} \\
\text { (SPAD) }\end{array}$ \\
\hline & \multicolumn{7}{|c|}{ planta $^{-1}$} \\
\hline \multicolumn{8}{|l|}{ Polímero (P) } \\
\hline Ausência & 0,68 & 91,85 & 18,43 & 73,42 & 25,18 & 101,83 & 28,57 \\
\hline Presença & 0,64 & 88,03 & 17,60 & 70,43 & 25,40 & 108,53 & 29,48 \\
\hline Teste F & $0,52 \mathrm{~ns}$ & $0,39 \mathrm{~ns}$ & $0,52 \mathrm{~ns}$ & $0,35 \mathrm{~ns}$ & $0,07 \mathrm{~ns}$ & $1,48 \mathrm{~ns}$ & $1,59 \mathrm{~ns}$ \\
\hline \multicolumn{8}{|l|}{ Paclobutrazol (Z) } \\
\hline 0 & 0,74 & 100,08 & 19,98 & 80,10 & 25,05 & 110,24 & 23,67 \\
\hline 38,5 & 0,69 & 93,00 & 18,48 & 74,52 & 24,96 & 107,46 & 29,65 \\
\hline 76,9 & 0,60 & 84,04 & 16,56 & 67,48 & 24,88 & 103,18 & 30,20 \\
\hline 115,4 & 0,61 & 82,64 & 17,04 & 65,60 & 26,28 & 99,84 & 32,60 \\
\hline Teste F & $1,53 \mathrm{~ns}$ & $1,79 \mathrm{~ns}$ & $1,81 \mathrm{~ns}$ & $1,73 \mathrm{~ns}$ & $0,65 \mathrm{~ns}$ & $0,69 \mathrm{~ns}$ & $27,95^{*}$ \\
\hline Regressão & - & - & - & - & - & - & L \\
\hline Teste $\mathrm{F}(\mathrm{P} \times \mathrm{Z})$ & $0,22 \mathrm{~ns}$ & $0,33 \mathrm{~ns}$ & $0,08 \mathrm{~ns}$ & $0,41 \mathrm{~ns}$ & $0,72 \mathrm{~ns}$ & $0,51 \mathrm{~ns}$ & $0,69 \mathrm{~ns}$ \\
\hline CV (\%) & 24,36 & 21,42 & 20,09 & 22,22 & 10,26 & 16,52 & 7,82 \\
\hline
\end{tabular}

* significativo $(\mathrm{p}<0,01)$; ns - não significativo; $\mathrm{L}$ - modelo linear.

da semente, por isso as quedas na emergência são menores que no teste de germinação.

Sementes recobertas apresentaram-se pouco vigorosas em condiçóes desfavoráveis de ambiente, representadas pelo teste de frio (Tabela 1). A peliculização não minimizou os danos decorrentes da embebição em condiçôes de baixa temperatura e alto grau de umidade. Isso propiciou maior perda de solutos celulares, desorganização das membranas celulares e, consequentemente, menor vigor (Marcos Filho, 2005).

O potencial fitotóxico do paclobutrazol à semente foi intensificado em condiçôes de estresse térmico na emergência de plântulas, como no teste de frio (Tabela 1). Temperaturas baixas durante a germinação propiciam a redução no metabolismo e na expressão da enzima esterase (Mertz et al., 2009). Essa enzima participa das reaçóes de hidrólise de ésteres na degradação de lipídios. Já o paclobutrazol ocasiona decréscimo de giberelinas ativas (GA1 e GA3) e aumento nos teores de ácido abscisico, culminando em menor biossíntese de $\alpha$-amilase, enzima chave no metabolismo de carboidratos (Lenton et al., 1994). Portanto, essa combinação entre baixas temperaturas e paclobutrazol prejudicou a degradação de substâncias de reservas, processo essencial na promoção da germinação e emergência de plântulas.

$\mathrm{Na}$ tabela 4 observa-se a interação entre os fatores estudados para a variável condutividade elétrica. Verifica-se que sementes náo revestidas tratadas com paclobutrazol (38,4 e 76,9 $\left.\mathrm{mg} \mathrm{L}^{-1}\right)$ apresentaram os maiores valores de 
Tabela 4. Condutividade elétrica de sementes de tomate (cultivar Kada Gigante) tratadas com polímero de revestimento e paclobutrazol

\begin{tabular}{ccc|} 
& \multicolumn{2}{c}{ Condutividade $\left(\mu \mathbf{S ~ c m}^{-1} \mathbf{g}^{-1}\right)$} \\
\cline { 2 - 3 } Paclobutrazol (mg L-1) & \multicolumn{2}{c|}{ Polímero } \\
\hline 0 & $101,50 \mathrm{a}$ & Presença \\
\hline 38,5 & $182,50 \mathrm{a}$ & $126,66 \mathrm{a}$ \\
76,9 & $258,63 \mathrm{a}$ & $104,61 \mathrm{~b}$ \\
115,4 & $169,00 \mathrm{a}$ & $158,43 \mathrm{a}$ \\
\hline
\end{tabular}

Médias seguidas de mesma letra na linha não diferem entre si pelo Teste de Tukey a $5 \%$ de probabilidade.

leitura de liberação de solutos durante a embebição. Isso também pode indicar que a peliculização propiciou maior retenção desse regulador para as sementes (Pereira et al., 2010; Smith, 1997). No entanto, a generalização dessa afirmação é restrita, visto que não houve interação entre os fatores estudados para as outras variáveis relacionadas ao potencial fisiológico das sementes e não há possibilidade de diferenciar tais solutos, ou seja, não há como separar a lixiviaçâo de paclobutrazol e de substâncias das sementes.

O uso do teste de condutividade elétrica é questionável quando se utilizam sementes tratadas quimicamente. A lixiviação de produtos químicos pode mascarar comparaçôes de vigor de sementes tratadas e não tratadas (Aguilera et al., 2000; Oliveira et al., 2011; Tropaldi et al., 2010). Portanto, não há como determinar os efeitos da interação entre o paclobutrazol e o polímero de revestimento no restabelecimento da integridade das membranas celulares durante a embebição.

A embebição de sementes com soluçóes de paclobutrazol diminuiu linearmente a altura de mudas (Tabela 2). Essa é a resposta morfológica mais esperada e conhecida desse regulador (Quinlan, 1981). As concentraçóes de $38,5 \mathrm{mg}$ $\mathrm{L}^{-1}, 76,9 \mathrm{mg} \mathrm{L}^{-1}$ e $115,4 \mathrm{mg} \mathrm{L}^{-1}$ ocasionaram uma redução de $9,94 \%, 20,95 \%$ e $24,02 \%$, respectivamente, quando comparadas ao controle. Resultados semelhantes foram observados em maça (Mage e Powell, 1990), tomate cv. Sun 6108, gerânio, marigold (Pasian e Bennett, 2001), cosmos (Pill e Gunter, 2001), tomate cv. Marglobe (Still e Pill, 2004) e tomate cv. Better Boy (Brigard et al., 2006). Além do condicionamento da altura de parte aérea, o paclobutrazol aumentou a relação diâmetro/altura (Tabela 2). Isso propicia a formação de uma muda compacta e mais resistente ao transplantio, devido à redução do excesso de crescimento vegetativo e menor possibilidade de quebras.

O paclobutrazol exerceu um impacto negativo sobre o vigor das sementes, bem como reduziu a velocidade e sincronismo na emergência (Tabela 1). No entanto, isso não prejudicou a habilidade das mudas acumularem massa de matéria seca e crescerem alometricamente o sistema radicular (Tabelas 2 e 3). Portanto, a reduçáo em altura observada náo pode ser atribuída à lentidão na emergência, mas ao efeito fisiológico principal desse composto, que consiste em inibir a biossíntese de giberelinas, principal hormônio associado ao alongamento caulinar (Tabela 2). Além disso, pode-se afirmar que houve um controle eficiente do crescimento sem alteraçôes da atividade fotossintética (Monselise e Goldschmidt, 1982).

A influência da embebição de sementes com paclobutrazol sobre o balanço entre fotossíntese e respiração depende de fatores exógenos e endógenos, ligados principalmente às interações entre genótipos e condiçốes ambientais. Still e Pill (2004) observaram que em condições de estresse térmico houve redução da massa de matéria seca de raiz e caule de mudas de tomate cv. Marglobe. Para mudas de pepino cv. Super Aston, nas mesmas condiçôes, as massas de matéria seca e fresca de caule e raiz aumentaram (Baninasab e Ghobadi, 2011). Na ausência de estressores ambientais, o paclobutrazol reduziu a massa de matéria seca de caule de mudas de tomate cultivar Better Boy (Brigard et al., 2006).

As mudas oriundas de sementes tratadas com paclobutrazol apresentaram folhas com coloraçáo verde mais intensa do que as do controle, o que pode ser comprovado pelos resultados das unidades SPAD (Tabela 3). Existem duas hipóteses que explicam a função do paclobutrazol na intensificação da coloração esverdeada da superfície assimilatória.

A primeira, comumente discutida, é que o paclobutrazol aumenta os níveis de citocininas endógenas e assim há maior diferenciação de cloroplastos, maior biossíntese e menor degradação de clorofila (Fletcher e Arnold, 1986). Isso normalmente é acompanhado de um crescimento do sistema radicular mais expressivo e de um aumento na eficiência fotossintética (Baninasab e Ghobadi, 2011; Sharma et al., 2011). No entanto, neste trabalho isso não pôde ser evidenciado, uma vez que não houve efeito do paclobutrazol nos parâmetros biométricos relacionados ao acúmulo de matéria seca, crescimento radicular e razão de área foliar (Tabelas 2 e 3 ).

A segunda hipótese refere-se ao efeito "concentrador" de clorofila nas folhas, devido à menor expansão foliar (Davies e Sankhla, 1987). O paclobutrazol atua de forma inversa no tamanho e na espessura foliar, sendo isso observado em várias espécies, tais como: Vitis spp. cv. Seyval Blanc (Hunter e Proctor, 1992), Citrus sinensis (L.) Osbeck cv. Valencia (Vu e Yelenosky, 1992), Poa pratensis L. (Beasley et al., 2007), Citrus volkameriana Pasq. (Siqueira et al., 2008), Saussurea costus (Falc.) Lipsch. (Chaturvedi et al., 2009) e Solanum tuberosum L. (Flores López et al., 2011). O efeito antigiberelina afeta o direcionamento de microtúbulos, essencial para a divisão e crescimento celular (Matsumoto, 2005). Portanto, não há maior biossíntese de clorofila e sim uma compartimentalização do conteúdo celular. Essa é a hipótese mais provável para este trabalho, devido à redução de área foliar (Tabela 2). A maior concentração utilizada $\left(115,4 \mathrm{mg} \mathrm{L}^{-1}\right)$ propiciou uma redução de $27,19 \%$ na área foliar e um aumento de $27,39 \%$ na detecção de clorofila em relação ao controle. 
Em relação à produção de mudas, a peliculização não alterou os parâmetros biométricos avaliados (Tabelas 2 e 3). Pereira et al. (2010) e Trentini et al. (2005) não observaram alterações derivadas da peliculização de sementes de soja com polímeros hidrofílicos na altura de plantas, nodulação, morfologia e produção de vagens. A produção de mudas de brócolos e salsa e o crescimento de plantas de cenoura também não foram afetados pelo revestimento de sementes (Hölbig et al., 2010; Tanada-Palmu et al., 2005). Dessa forma, observa-se que os efeitos da peliculização estáo mais restritos ao potencial fisiológico das sementes e, possivelmente, ao crescimento inicial de plântulas, durante um período relativamente curto após a emergência (Sampaio e Sampaio, 2009).

\section{CONCLUSÃO}

O uso do paclobutrazol é eficiente no condicionamento da altura de mudas de tomate cv. Kada Gigante, mas prejudica a germinação e o vigor de sementes. A peliculização não interfere na açáo do paclobutrazol sobre as sementes.

O teste de condutividade elétrica não é apropriado para avaliação do potencial fisiológico de sementes revestidas e tratadas com paclobutrazol.

\section{AGRADECIMENTOS}

Ao CNPq pela bolsa de mestrado, a primeira autora. À INCOTEC pela cessão do polímero de revestimento.

\section{REFERÊNCIAS}

ARNEY, S.E.; MANCINELL, P. The basic action of gibberelic acid in elongation of "meteor" pea stems. New Phytologist, v.65, p.161175, 1966. http://dx.doi.org/10.1111/j.1469-8137.1966.tb06349.x

AGUILERA, L.A.; CARON, B.O.; CELLA, W.L.; LERSCH JUNIOR, I. Qualidade fisiológica de sementes de milho em função da forma e do tratamento químico das sementes. Ciência Rural, v.30, p.211215, 2000. http://dx.doi.org/10.1590/S0103-84782000000200003

BANINASAB, B.; GHOBADI, C. Influence of paclobutrazol and application methods on high-temperature stress injury in cucumber seedlings. Journal of Plant Growth Regulation, v.30, p.213-219, 2011. http://dx.doi.org/10.1007/s00344-010-9188-2

BEASLEY, J.S.; BRANHAM, B.E.; SPOMER, A. Plant growth regulators alter Kentucky Bluegrass canopy leaf area and carbon Exchange. Crop Science, v.47, p.757-766, 2007. http://dx.doi. org/10.2135/cropsci2005.11.0432

BENINCASA, M.M.P. Análise de crescimento de plantas (noçóes básicas). Jaboticabal: Funep, 2003. 41p.
BEWLEY, J.D.; BLACK, M. Seeds: physiology of development and germination. New York: Plenum, 1994. 445p. http://dx.doi. org/10.1007/978-1-4899-1002-8

BRIGARD, J.P.; HARKESS, R.L.; BALDWIN, B.S. Tomato early seedling height control using a paclobutrazol seed soak. HortScience, v.41, p.768-772, 2006.

CHATURVEDI, A.K.; VASHISTHA, R.K.; PRASAD, P.; NAUTIYAL, C. Influence of foliar spray with paclobutrazol and ethepon on growth and photosynthetic behavior of Saussurea costus (Falc.) Lipsch. - an endangered medicinal and aromatic herb. Nature and Science, v.7, p.53-62, 2009.

DAVIES, T.D.; SANKHLA, N. Altered diurnal leaf movements in soybean seedlings treated with triazole growth regulators. Plant Cell Physiology, v.28, p.1345-1349, 1987.

DINIZ, K.A.; OLIVEIRA, J.A.; GUIMARÃES, R.M.; CARVALHO, M.L.M.; MACHADO, J.C. Incorporação de microrganismos, aminoácidos, micronutrientes e reguladores de crescimento em sementes de alface pela técnica de peliculização. Revista Brasileira de Sementes, v.28, p.37-43, 2006. http://dx.doi.org/10.1590/S010131222006000300006

DIZAJ, K.A. Seed coating of safflower (Carthamus tinctorius L.) in ordey to delay germination. African Journal of Plant Science, v.4, p.267-269, 2010.

FLETCHER, R.A.; ARNOLD, V. Stimulation of cytokinins and chlorophyll synthesis in cucumber cotyledons by triadimefon. Physiologia Plantarum, v.66, p.197-201, 1986. http://dx.doi. org/10.1111/j.1399-3054.1986.tb02408.x

FLORES LÓPEZ, R.; SÁNCHEZ, F.C.; PÉREZ, J.E.R. Paclobutrazol, uniconazol y cycocel en la producción de tubérculo-semilla de papa em cultivo hidropônico. Revista Chapingo - Serie Horticultura, v.17, p.173-182, 2011.

HÖLBIG, L.S.; BAUDET, L.; VILLELA, F.A.; CAVALHEIRO, V. Recobrimento de sementes de cenoura. Revista Brasileira de Sementes, v.32, p.22-28, 2010. http://dx.doi.org/10.1590/S010131222010000400003

HUNTER, D.M.; PROCTOR, J.J.A. Paclobutrazol affects growth and fruit composition of potted grapevines. HortScience, v.27, p.319-321, 1992.

LATIMER, J.G. Mechanical conditioning for control of growth and quality of vegetable transplants. HortScience, v.26, p.1456-1461, 1991.

LENTON, J.R.; APPLEFORD, N.E.J.; CROKER, S.J. Gibberellins and $\alpha$-amilase gene expression in germinating wheat grain. Plant Growth Regulations, v.15, p.261-270, 1994. http://dx.doi.org/10.1007/ BF00029899

LIMA, L.B.; SILVA, P.A.; GUIMARÁES, R.M.; OLIVEIRA, J.A. Peliculização e tratamento químico de sementes de algodoeiro (Gossypium hirsutum L.). Ciência e Agrotecnologia, v.30, p.1091-1098, 2006. http://dx.doi.org/10.1590/S1413-70542006000600007

MAGE, F.; POWELL, L. Inhibition of stratification and germination of apple seeds by paclobutrazol. HortScience, v.25, p.577, 1990.

MAGNITSKY, S.V.; PASIAN, C.C.; BENNETT, M.A.; METZGER, J.D. Controlling Plug Height of Verbena, Celosia, and Pansy by Treating Seeds with Paclobutrazol. HortScience, v.41, p.158-161, 2006a. 
MAGNITSKY, S.V.; PASIAN, C.C.; BENNETT, M.A.; METZGER, J. D.Effects of soaking cucumber and tomato seeds in paclobutrazol solutions on fruit weight, fruit size, and paclobutrazol level in fruits. HortScience, v.41, p.1446-1448, 2006b.

MAGUIRE, J.D. Speeds of germination-aid selection and evaluation for seedling emergence and vigor. Crop Science, v.2, p.176-177, 1962. http://dx.doi.org/10.2135/cropsci1962.0011183X000200020033x

MARCOS FILHO, J. Fisiologia de sementes de plantas cultivadas. Piracicaba: FEALQ, 2005. 495p.

MATSUMOTO, K. Giberelinas em plantas superiores: Síntese e propriedades fisiológicas. In: CID, P.B. (Ed.). Hormônios vegetais em plantas superiores. Brasília: Embrapa Recursos Genéticos e Biotecnologia, 2005. v.1, cap.3, p.91.

MERTZ, L.M.; HENNING, F.A.; SOARES, R.C.; BALDIGA, R.F.; PESKE, F.B.; DE MORAES, D.M. Alteraçóes fisiológicas de sementes de arroz expostas ao frio na fase de germinação. Revista Brasileira de Sementes, v.31, p.254-262, 2009. http://dx.doi.org/10.1590/S010131222009000200031

MONSELISE, S.P.; GOLDSCHMIDT, E.E. Alternative bearing in fruit trees. Horticultural Reviews, v.4, p.128-173, 1982.

OLIVEIRA, M.D.M.; NASCIMENTO, L.C.; ALVES, E.U.; GONÇALVES, E.P.; GUEDES, R.S.; SILVA NETO, J.J. Qualidade sanitária e fisiológica de sementes de Amburana cearensis A.C. Smith submetidas à termoterapia e tratamento químico. Acta Scientiarum. Agronomy, v.33, p.45-50, 2011.

PASIAN, C.C.; BENNETT, M. Paclobutrazol soaked marigold, geranium, and tomato seeds produce short seedlings. HortScience, v.36, p.721-731, 2001.

PEREIRA, C.E.; OLIVEIRA, J.A.; EVANGELISTA, J.R.E. Qualidade fisiológica de sementes de milho tratadas associadas a polímeros durante o armazenamento. Ciência e Agrotecnologia, v.29, p.12011208, 2005. http://dx.doi.org/10.1590/S1413-70542005000600014

PEREIRA, C.E.; OLIVEIRA, J.A.; NETO, J.C.; MOREIRA, F.M.S.; VIEIRA, A.R. Tratamentos inseticida, peliculização e inoculação de sementes de soja com rizóbio. Revista Ceres, v.57, p.653-658, 2010. http://dx.doi.org/10.1590/S0034-737X2010000500014

PILL, W.G.; GUNTER, J.A. Emergence and shoot growth of cosmos and marigold from paclobutrazol-treated seed. Journal of Environmental Horticulture, v.19, p.11-14, 2001.

QUINLAN, J.D. New chemical approaches to control of fruit tree form and size. Acta Horticulturae, v.1, p.95-106, 1981.

RADEMACHER, W. Growth retardants: effects on gibberellin biosynthesis and other metabolic pathways. Annual Review of Plant Physiology and Plant Molecular Biology, v.51, p.501-531, 2000. http://dx.doi.org/10.1146/annurev.arplant.51.1.501

SAMPAIO, T.G.; SAMPAIO, N.V. Recobrimento de sementes de hortaliças. In: NASCIMENTO, W.M. (Ed.). Tecnologia de sementes de hortaliças. Brasília: Embrapa Hortaliças, 2009. p.275-306.

SELEGUINI, A.; FARIA JÚNIOR, M.J.A.; BENETT, K.S.S.; LEMOS, O.L.; SENO, S. Estratégias para produção de mudas de tomateiro utilizando paclobutrazol. Semina: Ciências Agrárias, v.34, p.539548, 2013. http://dx.doi.org/10.5433/1679-0359.2013v34n2p539

SHARMA, D.K.; DUBEY, A.K.; SRIVASTAV, M.; SINGH, A.K.; SAIRAM, R.K.; PANDEY, R.N.; DAHUJA, A.; KAUR, C. Effect of putrescine and paclobutrazol on growth, physiochemical parameters, and nutrient acquisition of salt-sensitive citrus rootstock Karna khatta (Citrus karna Raf.) under $\mathrm{NaCl}$ stress. Journal of Plant Growth Regulation, v.30, p.301-311, 2011. http://dx.doi.org/10.1007/ s00344-011-9192-1

SIQUEIRA, D.L.; CECON, P.R.; SALOMÃO, L.C.C. Desenvolvimento do limoeiro "Volkmeriano" (Citrus volkameriana Pasq.) submetido a doses de paclobutrazol e ácido giberélico. Revista Brasileira de Fruticultura, v.30, p.764-768, 2008. http://dx.doi.org/10.1590/ S0100-29452008000300034

SMITH, S. Colorants and polymers: there is a difference. Seed World, v.135, p.26-27, 1997.

STILL, J.R.; PILL, W.G. Growth and stress tolerance of tomato seedlings (Lycopersicon esculentum Mill.) in response to seed treatment with paclobutrazol. Journal of Horticultural Science \& Biotechnology, v.79, p.197-203, 2004.

TANADA-PALMU, P.S.; PROENÇA, P.S.P.; TRANI, P.E.; PASSOS, F.A.; GROSSO, C.R.F. Recobrimento de sementes de brócolos e salsa com coberturas e filmes biodegradáveis. Bragantia, v.64, p.291297, 2005. http://dx.doi.org/10.1590/S0006-87052005000200016

TRENTINI, P.; VIEIRA, M.G.G.C.; CARVALHO, M.L.M.; OLIVEIRA, J.A.; MACHADO, J.C. Peliculização: Desempenho de sementes de soja no estabelecimento da cultura em campo na regiáo de Alto Garças, MT. Ciência e Agrotecnologia, v.29, p.84-92, 2005. http://dx.doi.org/10.1590/S1413-70542005000100010

TROPALDI, L.; CAMARGO, J.A.; SMARSI, R.C.; KULCZYNSKI, S.M.; MENDONÇA, C.G.; BARBOSA, M.M.M. Qualidade fisiológica e sanitária de sementes de mamona submetidas e diferentes tratamentos químicos. Pesquisa Agropecuária Tropical, v.40, p.89-95, 2010.

VU, J.C.V.; YELENOSKY, G. Growth and photosynthesis of sweet orange plants treated with Paclobutrazol. Journal of Plant Growth Regulation, v.11, p.85-89, 1992. http://dx.doi.org/10.1007/ BF00198019

WANG, S.Y.; SUN, T.; FAUST, M. Translocation of paclobutrazol, a gibberellin biosynthesis inhibitor, in apple seedlings. Plant Physiology, v.82, p.11-14, 1986. PMid:16664976 PMCid:PMC1056058. http:// dx.doi.org/10.1104/pp.82.1.11

WILLENBORG, C.J.; GUIDEN, R.H.; JOHNSON, E.N.; SHIRTLIFFE, S.J. Germination characteristics of polymer-coated canola (Brassica napus L.) seeds subjected to moisture stress at different temperatures. Agronomy Journal, v.96, p.786-791, 2004. http:// dx.doi.org/10.2134/agronj2004.0786

YESHITELA, T.; ROBBERTSE, P.J.; STASSEN, P.J.C. Paclobutrazol suppressed vegetative growth and improved yield as well as fruit quality of 'Tommy Atkins' mango (Mangifera indica) in Ethiopia. New Zealand Journal of Crop and Horticultural Science, v.32, p.281-293, 2004. http://dx.doi.org/10.1080/01140671.2004.9514307 